\title{
A Simple and Efficient Visible Light Photodetector based on Co304/ZnO Composite
}

\section{Aneela Tahira}

Linkopings universitet

\section{Raffaello Mazzaro}

Università di Bologna: Universita di Bologna

\section{Federica Rigoni}

Lulea University of Technology: Lulea Tekniska Universitet

\section{Ayman Nafady}

King Saud University

Shoyebmohamad F Shaikh

King Saud University

\section{Asma A. Al-Othman}

King Saud University

\section{Razan A. Alshgari}

King Saud University

Zafar Hussain lbupoto ( $\nabla$ zaffar.ibhupoto@usindh.edu.pk)

University of sindh Jamshoro https://orcid.org/0000-0002-6756-9862

\section{Research Article}

Keywords: ZnO nanorods, $\mathrm{Co304}$ nanosheets, heterojunction, visible light photodetector

Posted Date: June 11th, 2021

DOI: https://doi.org/10.21203/rs.3.rs-530646/v1

License: (c) (i) This work is licensed under a Creative Commons Attribution 4.0 International License.

Read Full License 


\section{Abstract}

Herein, we propose for the first time visible light photodetector based on n-type $\mathrm{ZnO}$ nanorods decorated with p-type $\mathrm{Co}_{3} \mathrm{O}_{4}$ nanowires. The heterojunction was fabricated on fluorine doped tin oxide (FTO) glass substrate by low temperature aqueous chemical growth method. ZnO exhibits nanorod morphology and cobalt oxide possesses nanowire shape with sharp tail. Energy dispersive spectroscopy (EDS) confirmed the presence of $\mathrm{Zn}, \mathrm{O}$, and $\mathrm{Co}$ elements in the heterojunction. $\mathrm{ZnO}$ and $\mathrm{Co}_{3} \mathrm{O}_{4}$ have hexagonal and cubic phases, respectively, as confirmed by XRD. The dense and perpendicular ZnO nanorods are acting as a scattering layer for visible light, while $\mathrm{Co}_{3} \mathrm{O}_{4}$ nanowires act as a visible-light absorber. The all oxide $\mathrm{p}$-n junction can operate as visible light photodetector. Furthermore, the heterojunction also shows a reproducible and fast response for the detection of visible light. Optimization of the device is needed (presence of buffer layers, tuning a thickness of the optical absorber) to improve its functionalities.

\section{Introduction}

The development of new architectures and materials combination for optoelectronic devices, like photodetectors, is boosting the research in the field. The main target is the development of low-cost processes to produce highly efficient and stable devices not containing harmful or expensive materials. An extended range of heterostructures for the photo detection application have been reported [1] like $\mathrm{BiOCl} / \mathrm{TiO}_{2}$ [2], grapheme/GaAs [3], $\mathrm{SnO}_{2} / \mathrm{NiO}$ [4], $\mathrm{SrTiO}_{3} / \mathrm{CuS}-\mathrm{ZnS}$ [5], $\mathrm{ZnO} / \mathrm{NiO}$ [6], Ag-doped $\mathrm{ZnO}$ [7], $\mathrm{ZnO} / \mathrm{Ga}_{2} \mathrm{O}_{3}[8]$.

It is worth to note mention here that these devices are limited by slow photo response ranging from millisecond to seconds and short wavelength sensing. Thus, it is highly desirable to sense the wide spectral range with swift switching response for the photodetector by using photosensitive compounds. The materials of earth abundant and nontoxicity are highly critical for the large scale application and mass production of devices in diverse ongoing research fields. The metal oxides of wide bandgap are found very potential materials for the design of efficient photodetector geometries. Among them, zinc oxide ( $\mathrm{ZnO})$ is n-type, wide band gap $(\sim 3.37 \mathrm{eV})$, emiconducting metal oxide, nontoxic and earth abundant in nature has been capitalized as active UV light absorber and used in in different highly sensitive photodetectors [9]. For making the p-n junction with $\mathrm{ZnO}$, the large utilization of $\mathrm{p}$-type metal oxides are (NiO), cuprous oxide $\left(\mathrm{Cu}_{2} \mathrm{O}\right)$, spinel cobalt oxide $\left(\mathrm{Co}_{3} \mathrm{O}_{4}\right)$ and so on [10-13].

Cobalt oxide $\left(\mathrm{CO}_{3} \mathrm{O}_{4}\right)$ has been highly investigated in various applications such as gas sensing [14], supercapacitors [15], Lithium ion batteries, [16] and in solar cells [17]. Like $\mathrm{Cu}_{2} \mathrm{O}, \mathrm{Co}_{3} \mathrm{O}_{4}$ is a p-type, earth abundant, non-toxic, semiconducting material. Its absorption spectrum is characterized by two direct transitions in the visible spectral range, corresponding to optical bandgaps of $1.5 \mathrm{eV}$ and $2.2 \mathrm{eV}[18,14]$. Thanks to the low bandgap, and the possibility to further optimize it. Generally it is believed that the $\mathrm{Co}_{3} \mathrm{O}_{4}$ exhibits spinel structure with mixed valence states. The $\mathrm{Co}_{3} \mathrm{O}_{4}$ being a p-type it is allowing the acceptor states which accelerates the trapping of charge thus it creates the charge transport. Because of 
the dual and indirect bandgaps of $\mathrm{Co}_{3} \mathrm{O}_{4} 2.2 \mathrm{eV}$ and $1.6 \mathrm{eV}$ and it in spinel structure it contains Co3p and Co $2 p$ spin states. It is a common observation that the dual bandgaps lead to the design of efficient photodetectors $[19,20]$. These unique features of $\mathrm{ZnO}$ and $\mathrm{Co}_{3} \mathrm{O}_{4}$ altogether share the development of wide spectral photodetectors. The $\mathrm{Co}_{3} \mathrm{O}_{4}$ nanostructures have been produced through different methods like solution, spray pyrolysis, and chemical vapor deposition [21-24].

The p-n junction of $\mathrm{ZnO}-\mathrm{CO}_{3} \mathrm{O}_{4}$ can be applied as efficient photodetector. A photosensor is a device, which generates photocurrent as a response to light. A photodiode is a device that converts light into electric current, commonly termed as photodetector, light detector or photosensor. Photodiodes typically work in reverse bias; the efficiency of these devices is mainly depending on the high surface charge carrier concentration [25]. Thus, in order to maximize the photo response, different kind of heterostructures were investigated, to exploit increased light absorption due to multiple scattering, and to increase the interface area, and maximize exciton dissociation rate at the interface [26-32]. Moreover, there are numerous heterostructures both inorganic and inorganic-organic photodetectors, which employ transparent n-type semiconducting metal oxides including $\mathrm{ZnO}$ because of its capability to absorb UV light efficiently [3336]. Beside this, $\mathrm{CO}_{3} \mathrm{O}_{4}$ as $\mathrm{p}$-type metal oxide can be a good light absorber for visible photodetectors due to its direct optical transitions in the visible range.

It is the simplicity, cost, processing nature and energy consumption during a growth method which are keep in mind for the mass production of nanostructured materials. For this purpose, there is no report about the $\mathrm{p}$-n junction of $\mathrm{Co}_{3} \mathrm{O}_{4} / \mathrm{ZnO}$ using low temperature aqueous chemical growth method for the development of visible light photodetector.

In this work, we investigated for the first time the system composed of hydrothermally grown $\mathrm{ZnO}$ nanorods covered by $\mathrm{CO}_{3} \mathrm{O}_{4}$ nanowires on fluorine doped tin oxide (FTO) glass, to be applied as photodetector. At the same time, the all oxide $\mathrm{p}-\mathrm{n}$ junction can act as visible-light photodetector with fast response and good stability.

\section{Experimental Section 2.1. Chemicals}

Zinc acetate di-hydrate, methanol $99 \%$, ethanol $99.5 \%$, potassium hydroxide, hexamethylenetetramine, cobalt chloride hexahydrate, urea, polyethylene glycol was purchased from Sigma-Aldrich. All the other chemicals used were of analytical grade. All the solutions were prepared in the distilled water.

\subsection{Synthesis of $\mathrm{ZnO} / \mathrm{Co}_{3} \mathrm{O}_{4}$ heterojunctions}

$\mathrm{ZnO}$ nanorods were fabricated on FTO glass substrate. First, a seed layer of $\mathrm{ZnO}$ nanoparticles was deposited on cleaned FTO substrate and annealed at $130{ }^{\circ} \mathrm{C}$ for 20 minutes. Annealing ensures the firm binding of $\mathrm{ZnO}$ seed particles on the substrate. The seed solution was prepared by mixing $0.274 \mathrm{~g}$ of zinc 
acetate di-hydrate in $125 \mathrm{~mL}$ of methanol and $0.109 \mathrm{~g}$ of $\mathrm{KOH}$ dissolved in $65 \mathrm{~mL}$ of methanol that was prepared separately. Then $\mathrm{KOH}$ solution was mixed dropwise in zinc acetate di-hydrate solution at constant stirring and temperature of $60^{\circ} \mathrm{C}$ for 2 hours. The growth solution was prepared by using equimolar concentration of $50 \mathrm{mM}$ of zinc nitrate hexahydrate and hexamethylenetetramine in the presence of $100 \mathrm{mg}$ of polyethylene glycol as soft template in $100 \mathrm{~mL}$ of distilled water. The seed layer coated FTO substrates were immersed in a beaker containing the growth solution, with the conducting side facing downwards. The beaker containing the growth solution was covered with aluminum foil tightly. Then the growth solution was kept in preheated electric oven for 4.5 hours at $95^{\circ} \mathrm{C}$. After the completion of the growth process, the substrates were gently washed with distilled water to remove the residual particles and dried at room temperature. $\mathrm{Co}_{3} \mathrm{O}_{4}$ nanostructures were prepared on the top of $\mathrm{ZnO}$ nanorods to obtain the composite heterostructures. $\mathrm{ZnO}$ nanorods were covered with seed particles of cobalt (prepared by mixing 0.68 grams in $30 \mathrm{~mL}$ methanol and 0.1 gram of $\mathrm{KOH}$ ) and annealed at $130{ }^{\circ} \mathrm{C}$ for $20 \mathrm{~min}$. A $0.1 \mathrm{M}$ solution of cobalt chloride hexahydrate and urea in $100 \mathrm{~mL}$ of water was prepared, containing $0.1 \mathrm{gram}$ of polyethylene glycol as templating agent. The $\mathrm{ZnO}$ nanorods coated with cobalt oxide seed particles were dipped in the growth solution. The growth solution was covered by aluminum foil and left in preheated electric oven for 4.5 hours at $95^{\circ} \mathrm{C}$. After the completion of the growth process, the samples were taken out from the beaker, washed with the distilled water, and dried at room temperature. Afterwards, cobalt hydroxide nanostructures were converted into $\mathrm{Co}_{3} \mathrm{O}_{4}$ by annealing in muffle furnace for 3 hours at $500{ }^{\circ} \mathrm{C}$ in air. Additionally, pristine $\mathrm{Co}_{3} \mathrm{O}_{4}$ nanostructures were prepared by the same method using equimolar $0.1 \mathrm{M}$ concentration of cobalt chloride hexahydrate and urea at $95{ }^{\circ} \mathrm{C}$ for 4.5 hours and consequently the obtained cobalt hydroxide phase was converted into oxide phase by annealing sample at $500{ }^{\circ} \mathrm{C}$ for 3 hours in air. The samples were characterized by SEM (FEI Magellan ${ }^{\text {TM }}$ HR-SEM) and XRD (Empyrean instrument, PANalytical PIXcel ${ }^{3 \mathrm{D}}$, with Cu Ka X-ray source, Bragg Brentano geometry) techniques. PV measurements were carried out at the illumination of air mass 1.5 global (AM 1.5G) using a solar simulator calibrated with a silicon calibrated solar cell. We used thermally evaporated circular gold back contacts, $55 \mathrm{~nm}$ thick and $2 \mathrm{~mm}$ in diameter. In addition, small portion of the deposited material on the FTO substrate was chemically etched and removed to access bare FTO for front contact. Similar method was used for making gold contacts on pure $\mathrm{ZnO}$ and cobalt oxide. The I-V characteristics of visible photodetector was measured by Solartron Analytical ModuLab XM multi-purpose potentiostat, using cyclic voltammetry at the bias voltage of -1 to $1 \mathrm{~V}$, either in dark or under illumination with an air mass 1.5 global (AM 1.5G) calibrate solar simulator. The photo response was recorded at $+1 \mathrm{~V}$ under chopped illumination. The transmittance and diffused reflectance for the various nanostructures were measured via Agilent UV-Visible spectrophotometer at room temperature in transmission mode and using an integrating sphere, respectively.

\section{Results And Discussion}

Figure 1 shows the fabrication process of all oxide heterojunctions composed of $\mathrm{ZnO}$ nanorods decorated with $\mathrm{Co}_{3} \mathrm{O}_{4}$ nanowires. Uniform, well aligned and dense $\mathrm{ZnO}$ nanorods grow perpendicular to the FTO substrate exhibiting hexagonal facets and were then covered with $\mathrm{Co}_{3} \mathrm{O}_{4}$ nanowires (Fig. 1). 
Figure 2 shows the cross-section image of pure $\mathrm{ZnO}$, pure $\mathrm{Co}_{3} \mathrm{O}_{4}$ and the heterojunction based on $\mathrm{Co}_{3} \mathrm{O}_{4}$ nanowires over the $\mathrm{ZnO}$ nanorods. $\mathrm{ZnO}$ nanorods are completely covered by grass-like nanowire structure of $\mathrm{Co}_{3} \mathrm{O}_{4}$. The surface of $\mathrm{ZnO}$ nanorods is etched during the deposition of $\mathrm{Co} 3 \mathrm{O} 4$ due to the use of cobalt chloride where chloride ion etched the top surface of $\mathrm{ZnO}$. The thickness of the $\mathrm{ZnO}$ layer is around 580 $\mathrm{nm}$ and the thickness of the compact $\mathrm{Co}_{3} \mathrm{O}_{4}$ layer is about 500 to $700 \mathrm{~nm}$. Some overgrown $\mathrm{Co}_{3} \mathrm{O}_{4}$ nanowires, a few microns in length, are visible in the cross-section image. The elemental distribution along the cross-section of the composite system indicates the presence of Zn, O, Co and Sn at the expected position. The EDS analysis revealed the homogeneous distribution of each element in the respective part of the heterojunction, suggesting that the $\mathrm{ZnO}$ underlying layer is maintained during the $\mathrm{Co}_{3} \mathrm{O}_{4}$ growth as shown in Fig. 2. Figure 3 is reporting the XRD analysis of the $\mathrm{ZnO} / \mathrm{Co}_{3} \mathrm{O}_{4}$ sample and the comparison the single components grown on FTO substrates. The XRD pattern of pure ZnO (Fig. 3b) exhibits the typical $\mathrm{ZnO}$ hexagonal crystal phase and the diffraction peaks are in good agreement with the standard JCPDS card no. 96-00-4182, in addition to some peaks coming from the FTO substrate (Fig. 3a as reference). The intense (002) peak is suggesting a c-axis oriented growth of $\mathrm{ZnO}$ nanorods, as previously reported [37]. XRD confirms the cubic phase of the $\mathrm{Co}_{3} \mathrm{O}_{4}$ structures, according to the standard JCPDS card no. 96-900-5889 as shown in Fig. 3 (c). The XRD pattern of the composite (Fig. 3(d)) indicates the presence of both hexagonal phase from $\mathrm{ZnO}$ and cubic phase from $\mathrm{Co}_{3} \mathrm{O}_{4}$, as expected. No spurious phases are detected in the sample, in good agreement with elemental composition obtained from EDS analysis.

UV-Visible transmittance spectrum and diffused reflectance of $\mathrm{ZnO}, \mathrm{Co}_{3} \mathrm{O}_{4}$ and $\mathrm{ZnO} / \mathrm{Co}_{3} \mathrm{O}_{4}$ structures are reported in Fig. 4 (a.b). ZnO sample is showing the typical band edge related drop in transmittance and reflectance below $375 \mathrm{~nm}$. For pristine cobalt oxide, a wide absorption band ranging from $300 \mathrm{~nm}$ to 550 $\mathrm{nm}$ is noticeable in transmission spectrum, with a second peak centered at $720 \mathrm{~nm}$, consistent with the double band-gap energy characterizing $\mathrm{Co}_{3} \mathrm{O}_{4}$. [38] The composite nanostructures exhibit strong absorption above $500 \mathrm{~nm}$ due to the thick $\mathrm{Co}_{3} \mathrm{O}_{4}$ layer. As the SEM results have proved, the $\mathrm{Co}_{3} \mathrm{O}_{4}$ top layer has also a NW structure, which can enhance light scattering. Since $\mathrm{Co}_{3} \mathrm{O}_{4}$ is a low bandgap semiconductor the trapped photons will be preferentially absorbed, rather than diffused, as in the case of ZnO." Such UV-Visible characteristics for $\mathrm{Co}_{3} \mathrm{O}_{4}$ and its composite agree with results in the literature [39].

In diffuse reflectance spectra (Fig. 4 (b), the highest intensity in the visible region is observed in ZnO nanorods, while it is drastically decreased for the composite and pure cobalt oxide nanostructures, due to strong light absorption from $\mathrm{Co}_{3} \mathrm{O}_{4}$. This is a promising result in terms of Sun light absorption from the composite heterostructures.

Figure 5(a) shows the response of visible light photodetector based on $\mathrm{Co}_{3} \mathrm{O}_{4} / \mathrm{ZnO}$ p-n junction in the dark and under simulated Sunlight. The current voltage $(I-V)$ response shows the typical behavior of a p-n junction, with the current increasing with the applied voltage in dark. A drastic increase of the steepness of the $\mathrm{I}-\mathrm{V}$ curve is recorded under illumination, indicating that a strong decrease of the device resistance is taking place, since the light absorption is producing an increase of the number of carriers due to the 
exciton generation and separation, and charge collection at the two electrodes. Importantly, high intensity of light and voltage can push faster photo-generated charge carriers towards the electrodes and minimizing the recombination of hole-electron pairs [40,41]. Figure $5(\mathrm{~b})$ shows the dependence of the current on time under on/off light for each interval of $20 \mathrm{~s}$. The rise in photocurrent is significant (in the ms regime) and become reasonably stable under illumination, while slowly decaying to the original current value. The slow decay of the OFF cycle suggests a low recombination rate of the generated charges, probably due to the limited conductivity of the $\mathrm{Co}_{3} \mathrm{O}_{4}$ layer. However, the photocurrent generated largely exceeds the limited increase in the baseline current observed in dark condition, in contrast to what happens in the pure $\mathrm{ZnO}$ sample (Fig. $6(\mathrm{c}, \mathrm{d})$ ). The repeatability and the large ON-OFF photocurrent ratio for this $\mathrm{Co}_{3} \mathrm{O}_{4} / \mathrm{ZnO}$ heterojunction suggest promising application as visible light photodetector.

\section{Conclusions}

In summary, a simple methodology is used for the first time for the fabrication of heterostructure based on $\mathrm{Co}_{3} \mathrm{O}_{4}$ nanowires decorated on $\mathrm{ZnO}$ nanorods by hydrothermal method. $\mathrm{ZnO}$ nanorods are completely covered by thick layer of $\mathrm{CO}_{3} \mathrm{O}_{4}$ nanowires, which is confirmed by the topographical and cross section SEM images. The $\mathrm{ZnO}$ layer exhibits a thickness of $580 \mathrm{~nm}$, whereas compact $\mathrm{Co}_{3} \mathrm{O}_{4}$ layer has thickness of 500 to $700 \mathrm{~nm}$. Both EDS and XRD studies are in good agreement by giving a definite information about the composition of heterostructures, which is comprised, on the $\mathrm{Co}_{3} \mathrm{O}_{4}$ and $\mathrm{ZnO}$ nanomaterials. The junction exhibits interesting features in terms of light responsivity rate and reliability, which suggest the application as visible light photodetector. Thanks to the extremely trivial and scalable synthetic approach, the presented $\mathrm{ZnO} / \mathrm{Co}_{3} \mathrm{O}_{4}$ is appealing for low power/low price photodetectors that can be employed in portable and wearable devices.

\section{Declarations}

\section{Acknowledgment}

A. N, S.F.S, A. A. A, and R. A. A extend their sincere appreciation to the Deanship of the Scientific Research at King Saud University for funding this project through Research Group (RG \#236)

\section{References}

1. Chen, C., Ouyang, W., Yang, W., Fang, X.: Recent Progress of Heterojunction Ultraviolet Photodetectors: Materials, Integrations, and Applications. Adv. Funct. Mater. 30, 1909-1923 (2020)

2. Ouyang, W., Teng, F., Fang, X.: High Performance BiOCl Nanosheets/TiO2 Nanotube Arrays Heterojunction UV Photodetector: The Influences of Self-Induced Inner Electric Fields in the BiOCl. Nanosheets.Adv. Funct. Mater. 28, 1707-1720 (2018)

3. Tao, Z., Zhou, D., Yin, H., Cai, B., Huo, T., Su, Y.: A facile method for preparation of emulsion using the high gravity technique.Mater. Sci. Semicond. Process. 111, 1049-1058 (2020) 
4. Long, Z., Xu, X., Yang, W., Hu, M., Shtansky, D., Golberg, D., Fang, F.: Monolayer Doping: A Shallow Acceptor of Phosphorous Doped in MoSe2 Monolayer Adv. Electron. Mater 6, 1901-1912 (2020)

5. Zhang, Y., Xu, X., Fang, X.: Tunable self-powered n-SrTiO3 photodetectors based on varying CuS-ZnS nanocomposite film (p-CuZnS, p-CuS, and n-ZnS). InfoMat 1, 542-551 (2019)

6. Zhang, Z., Ning, Y., Fang, X.: From nanofibers to ordered ZnO/NiO heterojunction arrays for selfpowered and transparent UV photodetectors. J. Mater. Chem. C. 7, 223-229 (2019)

7. Ning, Y., Zhang, Z., Teng, F., Fang, X.: Role of Surface RGD Patterns on Protein Nanocages in Tumor Targeting Revealed Using Precise Discrete Models. Small. 14, 1703-1712 (2018)

8. Zhao, B., Wang, F.,Chen,H., Zheng, L., Su, L., Zhao, D., Fang, F.: TpyCo2+-Based Coordination Polymers by Water-Induced Gelling Trigged Efficient Oxygen Evolution Reaction. Adv. Funct. Mater. 27, 17001711 (2017)

9. Ferhati, H., Djeffal, F., Benhaya, A.: Structural and electrical properties of Ba-substituted spinel ferrites.Mater. Sci. Semicond. Process. 119, 1049-1056 (2020)

10. Kumar, M., Patel, M., Kim, J., Kim, B.: Chemical epitaxy of $\pi-p h a s e$ cubic tin monosulphide. Mater. Lett 13, 122-125 (2018)

11. Zhang, D., Gu, X., Jing, F., Gao, F., Zhou, J., Ruan, S.: Studies on the Influence of Growth Time on the Rutile TiO2 Nanostructures Prepared on Si Substrates with Fabricated High-Sensitivity and FastResponse p-n Heterojunction Photodiode. J. Alloys Compd. 618, 551-554 (2015)

12. Chen, H., Liu, K., Hu, L., Ghamdi, A., Fang, X.: Ultraviolet Detectors Based on Wide Bandgap Semiconductor Nanowire: A Review. Mater. Today 18, 493-502 (2015)

13. Klochko, N.P., et al.: Structure and properties of nanostructured $\mathrm{ZnO}$ arrays and $\mathrm{ZnO} / \mathrm{Ag}$ nanocomposites fabricated by pulsed electrodeposition. Sol. Energy 164, 149-159 (2018)

14. Fu, Q.M., et al.: Tin-doped comb-like CdS microstructure and construction of the micro-sliding rheostat. Mater. Lett. 222, 74-77 (2018)

15. Rana, A.K., Park, J., Kim, J., Wong, C.: Nano energy for miniaturized systems. Nano Energy 64, 10391041 (2019)

16. Nam, H., Sasaki, T., Koshizaki, N.:Thickness and Morphology Effects on Optical Gas-Sensing Response Using Nanostructured Cobalt Oxide Films Prepared by Pulsed Laser Ablation. J. Phys. Chem.B. 110,110 - 21 (2006)

17. Patil, P., Kadam, L., Lokhande, C.: Preparation and characterization of spray pyrolysed cobalt oxide thin films. Thin Solid Films. 272, 29-39 (1996)

18. Barreca, D., Massignan, C.: Composition and Microstructure of Cobalt Oxide Thin Films Obtained from a Novel Cobalt(II) Precursor by Chemical Vapor Deposition. Chem. Mater. 13, 588-599 (2001)

19. Kandalkar, S., Gunjakar, J., Lokhande, C.: Preparation of cobalt oxide thin films and its use in supercapacitor application. Appl. Surf. Sci. 254, 5540-5549 (2018)

20. Chen, C., Buysman, A., Kelder, E.: Schoonman, J.: Electrostatic spray deposition of thin layers of cathode materials for lithium battery. Solid State Ionics. 80, 1261-1282 (1995) 
21. Ghamgosar, P., et al.: Self-Powered Photodetectors Based on Core-Shell ZnO-Co304 Nanowire Heterojunctions. ACS Appl. Mater. Interfaces 11, 23454-23462 (2019)

22. Kandalkar, S., Gunjakar, J., Lokhande, C.: Study of structural and electronic environments of hydrogenated amorphous silicon carbonitride (a-SiCN:H) films deposited by hot wire chemical vapor deposition. Appl. Surf. Sci. 254, 5540-5540 (2008)

23. Qiao, C., et al.: Nature of the band gap and origin of the electro-/photo-activity of Co304.J. Mater. Chem. C 1, 4628-4633 (2013)

24. Cheng, C., Serizawa, M., Sakata, H., Hirayama, T.: Electrical conductivity of Co3O4 films prepared by chemical vapour deposition. Mater. Chem. Phys 53, 225-230 (1998)

25. Zou, X., Su, J., Silva, R.: Efficient oxygen evolution reaction catalyzed by low-density Ni-doped Co304 nanomaterials derived from metal-embedded graphitic C3N4. Chem. Commun. 49, 7522-7524 (2013)

26. Jiao, F., Frei, H.: Nanostructured cobalt and manganese oxideclusters as efficient wateroxidationcatalysts. Energy Environ. Sci. 3, 1018-1027 (2006)

27. Nam, H., Sasaki, T., Koshizaki, N.: Structure and Stability of Silver Nanoparticles in Aqueous Solution Produced by Laser Ablation.J. Phys. Chem.B. 110,253 - 62 (2006)

28. Patil, P., Kadam, L., Lokhande, C.: Preparation and Characterization of Sprayed Cobalt Oxide Thin Films.Thin Solid Films. 29,272 - 81 91996)

29. Barreca, D., Massignan, C.: Composition and Microstructure of Cobalt Oxide Thin Films Obtained from a Novel Cobalt(II) Precursor by Chemical Vapor Deposition. Chem. Mater. 13, 588-596 (2001)

30. Kandalkar, S., Gunjakar, J., Lokhande, C.: Preparation of cobalt oxide thin films and its use in supercapacitor application. Appl. Surf. Sci. 254, 5540-5553 (2008)

31. Chen, C., Buysman, A., Kelder, E., Schoonman, J.: Solid State Ionics Special Issues. Solid State Ionics 13, 80-91 (1995)

32. Wu, W., Ting, J., Chang, C.: Zinc(ii) coordination polymers with substituted benzenedicarboxylate and tripodal imidazole ligands: syntheses, structures and properties.CrystEngComm. 12, 1433-42 (2010)

33. Green.M.: Solar cell efficiency tables.Prog photovoltic Res Appl, 9,123 - 35 (2001)

34. Rana, A.,K., Patel, M., Nguyen, T., Yun, T., Kim, J.-H.: Jo., Mater. Sci. Semicond. Process. 117, 105192 (2020)

35. Mahala, P., Patel, M., Ban, D.-K., Nguyen, T.,T., Yi, J., Kim, J.: Journal of Alloys and Compound. 827, $154376(2020)$

36. Veeralingam, S., Yadav, P., Badhulika, S.: Nanoscale. 12, 9152-9161 (2020)

37. Khun, K., Ibupoto, Z., AlSalhi, M., Atif, M., Ansari, A., Willander, M.: Fabrication of Well-Aligned ZnO Nanorods Using a Composite Seed Layer of ZnO Nanoparticles and Chitosan Polymer. Materials 6, 4361-4373 (2013)

38. Chen, J., Wu, X., Selloni, A.: Electronic structure and bonding properties of cobalt oxide in the spinel structure. Phys. Rev. B 83, 2452-2465 (2011) 
39. Jana, T., Pal, A., Chatterjee, K.: Photoluminescent Properties of ZrO2: Tm3+, Tb3+, Eu3 + PowdersA.Combined Experimental and Theoretical Study.J. Alloys Compd. 653 - 64: (2015)

40. Xia, J., Zhu, D., Li, X., Wang, L., Tian, L., Li, J., Huang, X.: Meng.X.: Highly sensitive photodetectors based on hybrid 2D-OD SnS2-copper indium sulfide quantum dots.Adv. Funct. Mater. 26, 4673-4684 (2016)

41. Fu, Y., Gou, G., Wang, X., Chen, Y., Wan, Q., Sun, J., Xiao, S., Huang, H.: Dai.G.: Pressure Effects on Structure and Optical Properties in Cesium Lead Bromide Perovskite Nanocrystals. Appl. Phys. A Mater. Sci. Process. 22, 123-132 (2017)

\section{Figures}
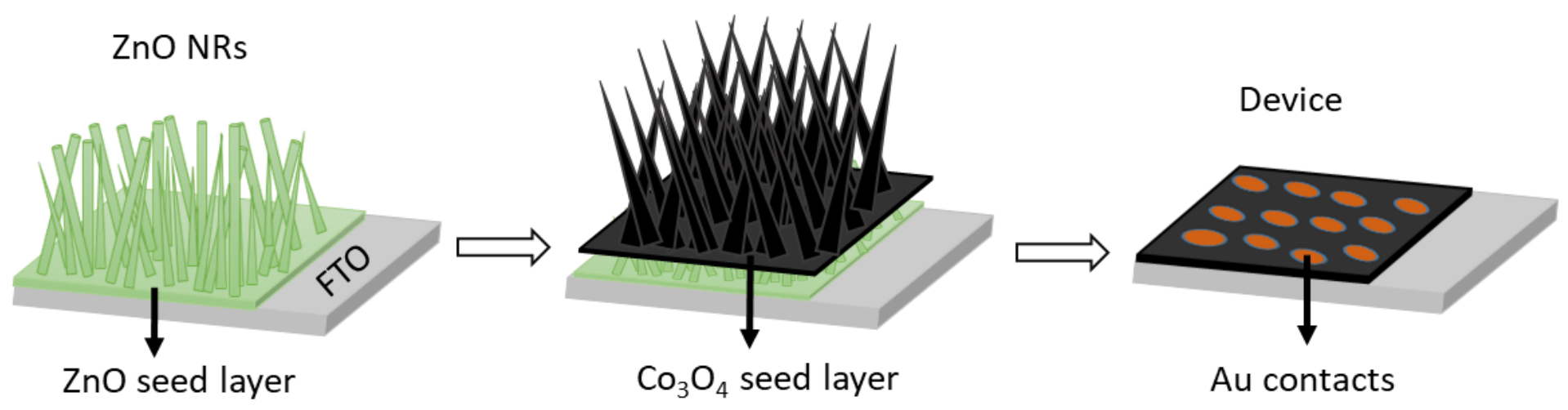

a

b
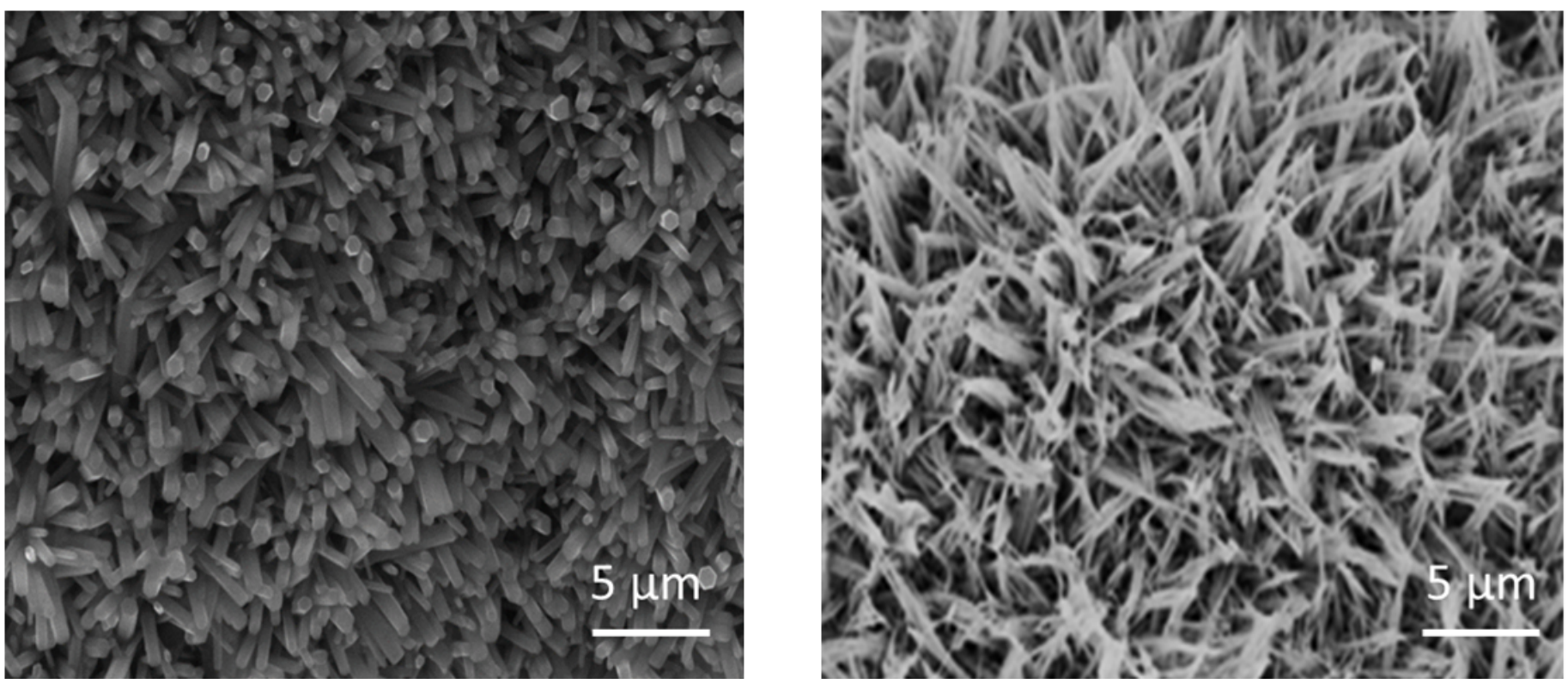

\section{Figure 1}

A schematic diagram is describing the fabrication process of photovoltaic device based on Co304 deposited on ZnO nanorods (a) SEM image for pure ZnO nanorods, (b). Co304/ZnO nanorods SEM images 


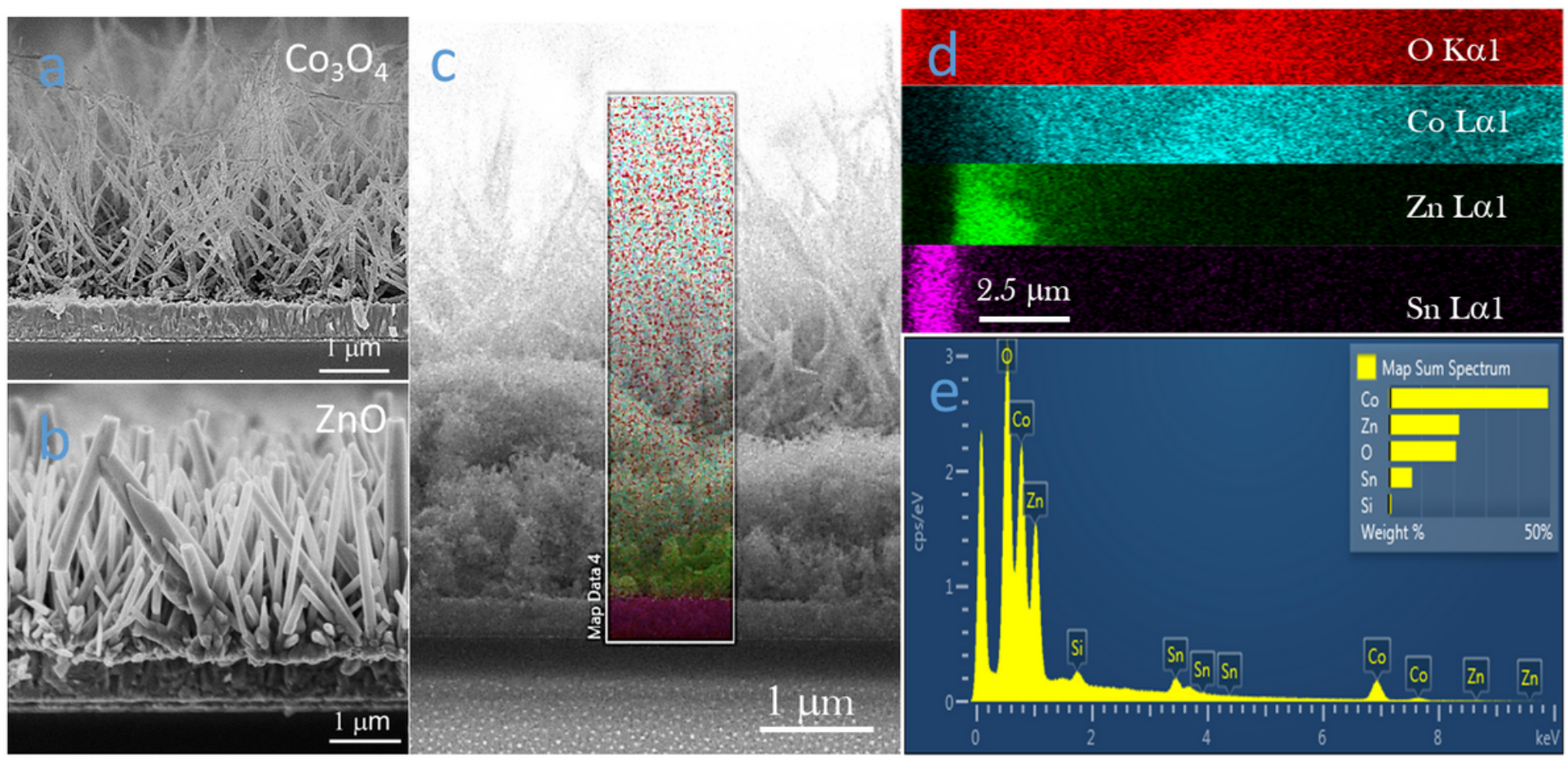

Figure 2

The cross-section SEM images of a) pure $\mathrm{ZnO}, \mathrm{b}$ ) pure Co304, and c) the $\mathrm{ZnO}$ covered with Co304 nanorods along with $\mathrm{d}$ ) the elemental distribution in their heterostructures and a representative EDS spectrum (e). 


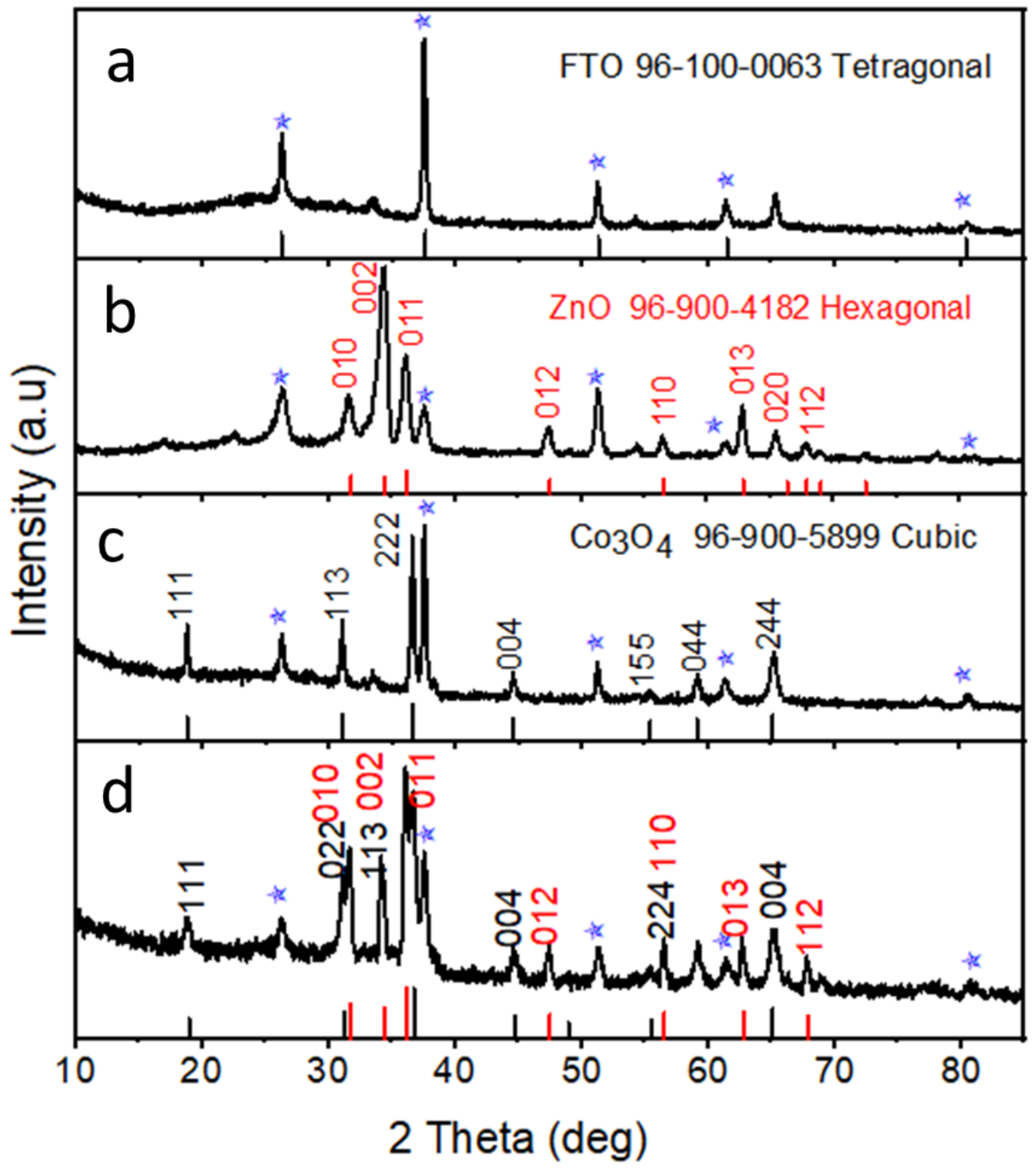

Figure 3

a. XRD of FTO, b. The XRD of pure ZnO nanorods, c. The XRD of Co304 d. The XRD of Co304 / ZnO nanorods by low temperature aqueous chemical growth method 
a

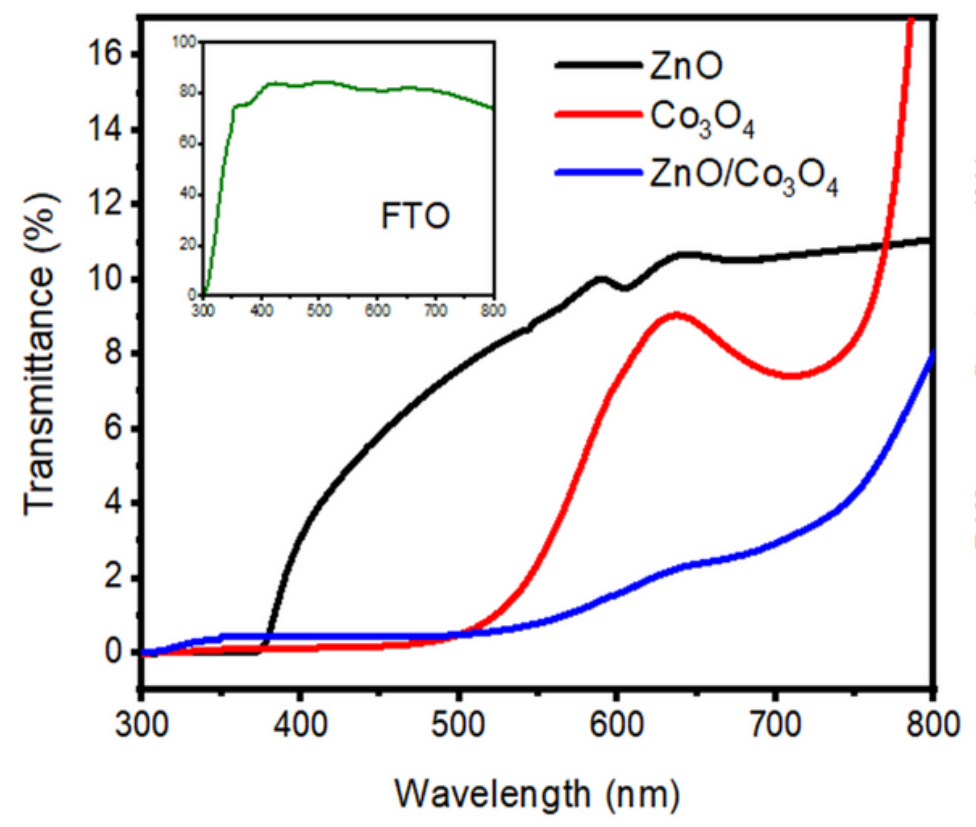

b

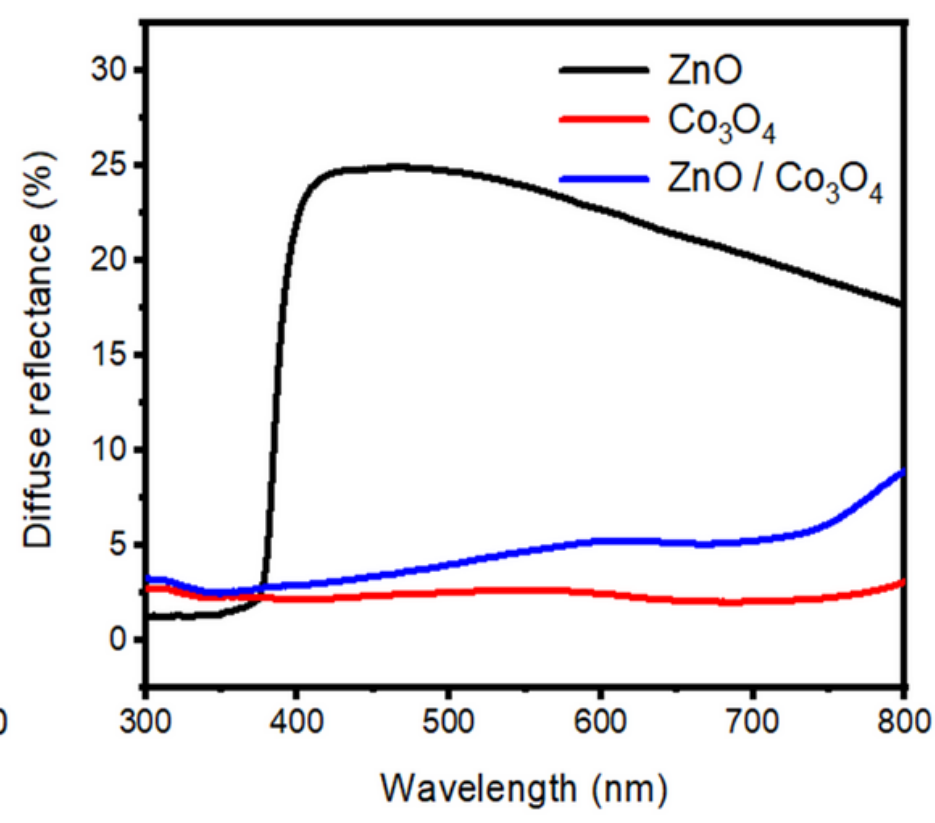

Figure 4

The optical transmittance and diffused reflectance of various materials used in the fabrication of Co304 decorated $\mathrm{ZnO}$ nanorods 

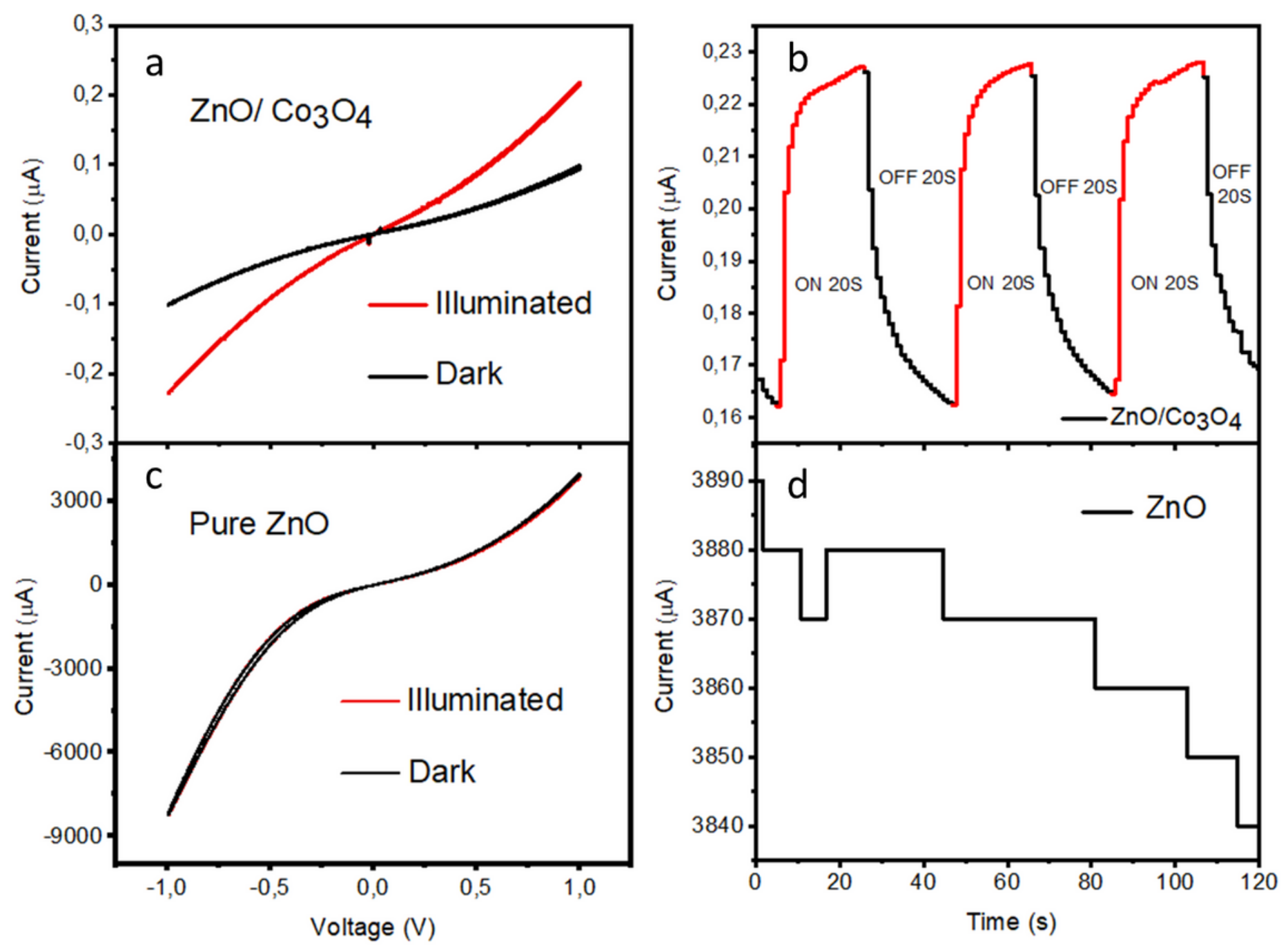

Figure 5

a. I-V characteristics of visible light photodetector, b. on/off light response of developed photosensor at bias voltage of $1.0 \mathrm{~V}$, c. I-V curve of pure $\mathrm{ZnO}$, d. on/off light response of pure $\mathrm{ZnO}$. 